\title{
A METAL CAST OF THE ANTERIOR SEGMENT OF THE EYEBALL MADE IN THE LIVING HUMAN SUBJECT
}

BY

\author{
James MoOres BALl, M.D. \\ St. Louis, Missouri
}

THE following case seems to be of such an unusual character as to deserve recording.

Mr. E. H., a farmer, aged 28 years, late in January, 1924, was injured by the explosion of a pot of molten lead. He suffered numerous burns of the face and neck, and the loss of his right eye.

Four days later his physician, Dr. W. F. Grayson, of Granite City, Illinois, after having separated the swollen eyelids,

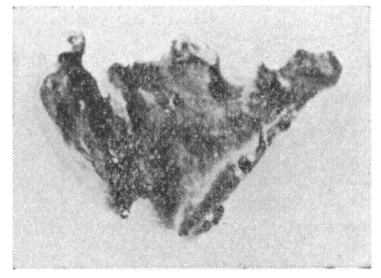

FIG. 1.

Corneal surface of cast. $\times 2$.

discovered the metal cast which is shown in the accompanying photographs. Dr. Grayson states that the cast was centrally placed; that it was held in situ by the eyelids; and that it fell out after the lids had been forcibly separated. He also states that the smoother surface of the cast is the one which had been in contact with the cornea; and that the cast was placed with its longest diameter in the horizontal meridian.

The cast weighs 12.5 grains. Its longest diameter measures 18 millimetres. Its greatest vertical diameter is 12 millimetres. Eleven days after the injury the writer enucleated the eye-in two segments. The anterior ocular and orbital tissues were necrotic : the strabismus hook, for example, met with no resistance. The orbit was treated as an open wound with frequent changes of the dressing.

The accompanying photographs show : (1) The corneal surface of the cast, $\times 2 ;(2)$ the palpebral surface, $\times 2$; and (3) appearance of the patient on the seventy-first day after the injury. 


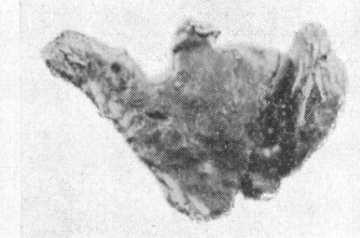

FIG. 2.

Palpebral surface of cast. $\times 2$.

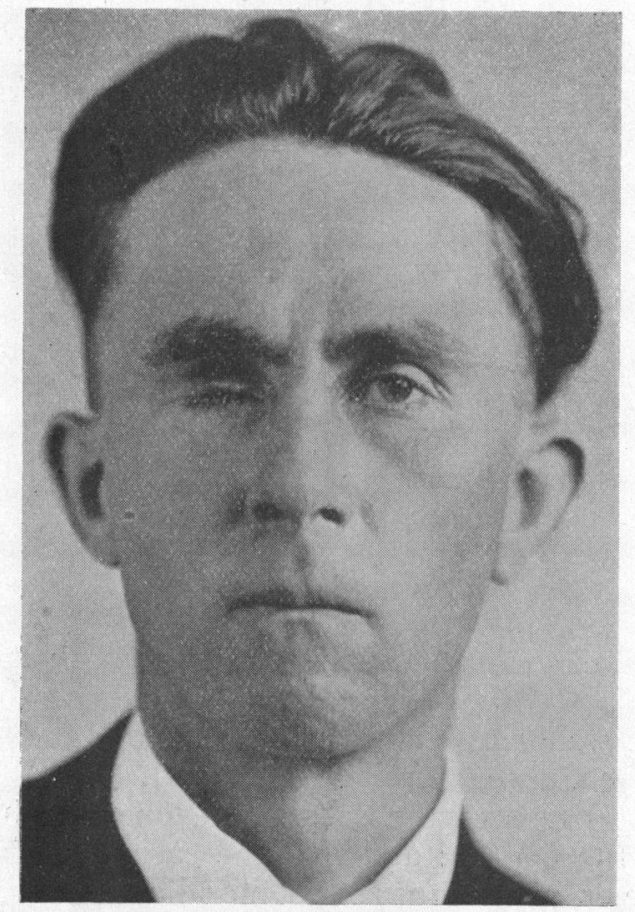

FIG. 3.

Appearance of the patient, seventy-one days after the injury.

The inter-palpebral fissure on the traumatised side is 5 millimetres shorter than its fellow; the lid-margins are adherent to the extent of 6 millimetres, in the middle third; and this is the only permanent damage sustained by the eyelids.

An account of this case, with accompanying photographs, was sent to Dr. A. J. Ballantyne, of Glasgow, and was shown at the 
annual meeting of the Ophthalmological Society of the United Kingdom, Glasgow, May 1-3, 1924. It was received too late for insertion in the official programme and was not published.

In a personal. communication, under date of April 8, 1924, Dr. Ballantyne wrote: "I have occasionally seen things a little like yours, where a small splash of molten metal has been gripped between the lids, but I have never seen one in which so extensive a cast of the parts has been made."

Naturally, the question will be asked: "How did the eyelids escape with such slight damage, while the eyeball was destroyed and much of the content of the orbit was cooked?"

The answer must be this: "At the moment of explosion the patient's eyes were opened widely; the boiling metal, in the form of a sphere, must have struck the cornea centrally ; instantaneously closure of the eyelids followed, helping to flatten the molten metal into the shape which the cast bears. Under any other situation the eyelids must have sustained a much greater damage."

\title{
AVOIDANCE OF POST-OPERATIVE INFECTION IN CATARACT OPERATIONS
}

\author{
$\mathrm{BY}$
}

\author{
B. P. Banaji, F.R.C.S.I. \\ BOMBAY
}

THE exceptionally good results that I have obtained in my last series of 500 cases of cataract operations as regards freedom from infection has induced me to publish this communication. In this series of 500 operations only one eye was lost by irido-cyclitis, and even in this particular case the iritis developed ten days after the operation, when the patient had left the hospital. Every operator of experience knows how impossible is the treatment of panophthalmitis after an ocular operation and how difficult and trying the management of severe iritis can be. No amount of energy therefore could be said to be ill spent in trying to avoid septic infection after cataract operations, and one is justified in using all the available precautions against sepsis, even though some of them may seem superfluous.

\section{Choice of Operation}

It would not be out of place here to discuss the relative merits of the two methods of extraction in vogue in India, especially from the point of view of post-operative infection. 